\title{
Efeitos de Fontes Nitrogenadas com Distintas Degradabilidades sobre o Aproveitamento da Fibra, do Nitrogênio e do Amido em Rações para Bovinos 1
}

\author{
Míriam Silvânia de Souza², Jane Maria Bertocco Ezequiel ${ }^{3}$, Paulo Rossi Júnior ${ }^{4}$, \\ Euclides Braga Malheiros ${ }^{3}$
}

RESUMO - O objetivo do experimento foi avaliar os efeitos da utilização do farelo de soja ou da glutenose sobre a degradabilidade ruminal in situ dos constituintes de dietas compostas por feno, milho e as fontes nitrogenadas fornecidas para bovinos adultos com 650 $\mathrm{kg}$ de peso. A glutenose foi considerada fonte nitrogenada de baixa degradabilidade e o farelo de soja, de média degradabilidade ruminal. As degradabilidades potenciais obtidas para o nitrogênio foram 39,7 e 90,3\% e as degradabilidades efetivas 35,7 e 62,9\%, respectivamente, para glutenose e farelo de soja. Utilizou-se a fibra mordente para determinar a taxa de passagem das dietas e obtiveram-se $6,6 \% / \mathrm{h}$ para dietas com farelo de soja e $2,4 \% / \mathrm{h}$ para dietas com glutenose. Não houve diferença na degradabilidade potencial da matéria seca do feno, nas frações A, B, C e na taxa de degradação, mas a degradabilidade efetiva da matéria seca foi inferior para as dietas com farelo de soja (29,3 vs 40,6\%). Os demais ingredientes, à exceção do milho, apresentaram acentuadas diferenças entre as dietas nas variáveis de degradabilidade, na taxa de degradação e na degradabilidade efetiva do nitrogênio, com inferioridade na dieta com glutenose. O milho diferiu apenas quanto à degradabilidade efetiva do nitrogênio, superior na dieta com glutenose (68,7 vs 56,3\%). O amido do milho apresentou menor degradabilidade efetiva na dieta com farelo de soja $(52,5 \mathrm{vs} 68,0 \%)$, sendo a degradabilidade efetiva da fibra do feno também inferior para essas dietas $(27,3$ vs $43,2 \%)$. Concluiu-se que fontes nitrogenadas com distintas degradabilidades podem afetar tanto a degradabilidade da fibra do volumoso quanto à do amido da própria fonte nitrogenada e do milho das dietas.

Palavras-chave: degradabilidade ruminal, fibra, amido, nitrogênio, fontes nitrogenadas

\section{Effects of Nitrogen Sources Degradability on the Use of the Fiber, Nitrogen and Starch of Bovine Diets}

\begin{abstract}
The objective of this experiment was to evaluate the effect of utilization of soybean meal or corn gluten meal on in situ ruminal degradabilities of diets, based on coastcross hay, corn and one of the nitrogen sources, fed to bulls, with average weight of $650 \mathrm{~kg}$. Corn gluten meal was considered as a nitrogen source of low degradability and the SBM as intermediate ruminal degradability. They presented nitrogen potencial degradability of 39.7 and $90.3 \%$ and effective degradability of 35.7 and 62.9 , for the corn gluten meal and soybean meal, respectively. It was used mordant fiber to determine the rate of passage of the diets and it was obtained $6.6 \% / \mathrm{h}$ for diets with soybean meal and $2.4 \% / \mathrm{h}$ for diets with corn gluten meal. There was no difference in the potential degradability of the dry matter of the hay, in the fractions A, B, C and in the degradation rate, but the effective degradability of dry matter was lower for diets with soybean meal (29.3 vs 40.6\%). For the nitrogen the ingredients, except corn, presented marked differences among diets in the fractions of degradability, in the degradation rate and in the effective degradability, being inferior in the diet with corn gluten meal. The corn differed only in the effective degradability of the nitrogen, being superior in the diet with corn gluten meal (68.7 vs $56.3 \%)$. The corn-starch presented lower effective degradability in the diet with soybean meal (52.5 vs 68.0\%) and the effective degradability of the hay fiber also was inferior for these diets (27.3 vs $43.2 \%)$. It was concluded that nitrogen sources with distinct degradabilities can affect the degradability of the fiber of the roughage, as well as the degradability of the starch of the nitrogen source or the corn of diets.
\end{abstract}

Key Words: fiber, nitrogen, nitrogen sources, ruminal degradability, starch

\section{Introdução}

Trabalhos recentes compilados pelo NRC (1996) e NRC (2001) têm indicado que a taxa de degradação do alimento no rúmen provoca profundo efeito nos produtos finais da fermentação e, conseqüentemente, no desempenho animal. Existem resultados contradi- tórios sobre o efeito da dieta no desaparecimento da matéria seca e da proteína incubadas no rúmen. Segundo McAllan et al. (1988), a digestão da fibra no ambiente ruminal pode ser afetada pelo teor de proteína das dietas, principalmente quando baseadas em forragens de baixa qualidade, uma vez que a deficiência de proteína limitaria a atividade ruminal,

\footnotetext{
${ }^{1}$ Parte da tese de Mestrado apresentada à FCAV/UNESP - Jaboticabal, SP

2Professora da FAZU e UNIUBE - Uberaba, MG. E.mail: miriam@fazu.br

${ }^{3}$ Professor da FCAV/UNESP - Jaboticabal, SP.

${ }^{4}$ Professor do Departamento de Zootecnia da UFPR - Curitiba - PR.
} 
afetando, assim, a ingestão e a digestibilidade dos nutrientes.

Stokes et al. (1991) formularam dietas contendo três níveis de carboidratos não estruturais $(38,31 \mathrm{e}$ $21 \%$ da matéria seca) e variaram as concentrações de proteína degradável, 13,2; 11,8 e 9,0\% da matéria seca. A finalidade do estudo foi verificar os efeitos da relação carboidrato não estrutural e proteína degradável no metabolismo bacteriano ruminal. Com o aumento na concentração de proteína degradável, aumentaram tanto a eficiência de síntese bacteriana e produção de AGV quanto a digestão da fibra, suportando a idéia de que tanto a proteína degradável quanto o carboidrato não estrutural são necessários para aumentar a digestão ruminal.

Polan et al. (1991), suplementando vacas lactantes de alta produção com farelo de soja ou glutenose e combinações de metionina e lisina sobrepassantes ruminal, observaram que a performance lactacional de vacas alimentadas com farelo de soja foi melhor do que a de vacas alimentadas com glutenose sem a adição de aminoácidos.

Os objetivos deste trabalho foram verificar os efeitos das concentrações de proteína degradável no rúmen sobre as taxas de passagem e a cinética de degradabilidade da glutenose, do farelo de soja, do milho e do feno das dietas.

\section{Material e Métodos}

Foram utilizados três bovinos machos, da raça holandesa, com peso vivo médio de $650 \mathrm{~kg}$ e três anos e meio de idade.

O experimento constou de dois períodos de vinte e quatro dias de duração, sendo vinte e um para adaptação aos alimentos e três dias para a colheita de dados. As dietas utilizadas foram compostas por $40 \%$ de feno de capim-coastcross e $60 \%$ de concentrado, representado pelo farelo de soja ou glutenose como fontes nitrogenadas e milho para acerto da energia, perfazendo dois tratamentos: um com alta PDR, conferida pelo farelo de soja, e outro com baixa PDR, conferida pela glutenose. As dietas foram formuladas para mantença, segundo o NRC (1989), e as composições percentuais se encontram na Tabela 1. A composição dos ingredientes das dietas encontrase na Tabela 2.

As dietas foram oferecidas duas vezes ao dia, com permanente disposição de água e sal mineralizado. As degradabilidades potenciais do feno, do farelo de
Tabela 1 - Composição química e percentual das dietas experimentais

Table 1 - Chemical and percentual composition of the experimental diets

\begin{tabular}{|c|c|c|}
\hline \multirow[t]{2}{*}{$\begin{array}{l}\text { Composição percentual } \\
\text { Percentual composition }\end{array}$} & \multicolumn{2}{|c|}{$\begin{array}{l}\text { Dieta } \\
\text { Diet }\end{array}$} \\
\hline & $\begin{array}{c}\text { Farelo de soja } \\
\text { Soybean meal }\end{array}$ & $\begin{array}{c}\text { Glutenose } \\
\text { Corn gluten meal }\end{array}$ \\
\hline $\begin{array}{l}\text { Feno } \\
\text { Hay }\end{array}$ & 39,4 & 39,4 \\
\hline $\begin{array}{l}\text { Farelo de soja } \\
\text { Soybean meal }\end{array}$ & 12,2 & - \\
\hline $\begin{array}{l}\text { Glutenose } \\
\text { Corn gluten meal }\end{array}$ & - & 8,6 \\
\hline $\begin{array}{l}\text { Milho } \\
\text { Corn } \\
\text { Composição química } \\
\text { Chemical composition }\end{array}$ & 48,4 & 52,0 \\
\hline $\begin{array}{l}\mathrm{PB}(\% \mathrm{MS}) \\
C P(\% D M)\end{array}$ & 15,0 & 15,0 \\
\hline $\begin{array}{l}\mathrm{PDR}(\% \mathrm{~PB}) \\
R D P(\% C P)\end{array}$ & 80,3 & 60,3 \\
\hline $\begin{array}{l}\text { Ingestão observada }(\mathrm{kg} \mathrm{M} \\
\text { Observed intake }(\mathrm{kg} D M)\end{array}$ & AS) & 10,2 \\
\hline
\end{tabular}

Tabela 2 - Composição química dos ingredientes das dietas experimentais

Table 2 - Chemical compositions of ingredients of the experimental diets

\begin{tabular}{|c|c|c|c|c|}
\hline \multicolumn{2}{|c|}{$\begin{array}{l}\text { Componente } \\
\text { Component }\end{array}$} & \multicolumn{2}{|c|}{$\begin{array}{c}\text { Alimento } \\
\text { Feed }\end{array}$} & \multirow[b]{2}{*}{$\begin{array}{l}\text { Feno } \\
\text { Hay }\end{array}$} \\
\hline & $\begin{array}{c}\text { Farelo de soja } \\
\text { Soybean meal }\end{array}$ & $\begin{array}{l}\text { Milho } \\
\text { Corn }\end{array}$ & $\begin{array}{c}\text { Glutenose } \\
\text { Corn gluten meal }\end{array}$ & \\
\hline \multirow{2}{*}{$\begin{array}{l}\text { MS } \\
D M\end{array}$} & 91,9 & 88,3 & 91,1 & 90,3 \\
\hline & \multicolumn{4}{|c|}{$\begin{array}{l}\% \mathrm{MS} \\
\% \mathrm{DM}\end{array}$} \\
\hline $\mathrm{EE}^{1}$ & 0,8 & 3,0 & 0,9 & 0,9 \\
\hline $\begin{array}{l}\text { Cinzas } \\
\text { Ash }\end{array}$ & 6,0 & 1,3 & 1,3 & 5,5 \\
\hline $\begin{array}{l}\mathrm{PB} \\
C P\end{array}$ & 49,5 & 8,9 & 53,0 & 9,7 \\
\hline $\begin{array}{l}\text { Amido } \\
\text { Starch }\end{array}$ & 8,9 & 65,4 & 38,0 & - \\
\hline
\end{tabular}

${ }^{1} \mathrm{EE}=$ extrato etéreo (Ether extract).

soja, do milho e da glutenose foram determinadas por intermédio da técnica dos sacos de náilon proposta por Mehrez \& Orskov (1977) e as efetivas, segundo Orskov \& McDonald (1979).

Utilizaram-se as taxas de passagem obtidas, experimentalmente, para cada dieta. A determinação da taxa de passagem da fase sólida das dietas foi feita através da fibra marcada com cromo mordente des-

R. Bras. Zootec., v.31, n.5, p.2139-2148, 2002 
crita por Úden et al. (1980), utilizando-se como indicador cana-de-açúcar triturada e mordantada com cromo, na proporção de $120 \mathrm{~g}$ por animal,ministrada em dose singular. Foram colhidas amostras de fezes diretamente do reto nos horários $0,12,16,20,24,28$, $32,36,42,48,54,60,72,84,96$ e 120 horas após a introdução da fibra mordantada. As amostras foram congeladas e, posteriormente, analisadas para determinação do cromo, segundo Pereira e Rossi Jr (1994). A taxa de passagem foi obtida através da regressão do logaritmo natural (ln) das concentrações de cromo nas fezes correspondentes aos tempos de colheita.

As amostras de feno foram moídas em moinho com peneira de $4 \mathrm{~mm}$ de malha e os demais alimentos foram moídos a $2 \mathrm{~mm}$. Os sacos, de 14 x $7 \mathrm{~cm}$, foram confeccionados em náilon $100 \%$ poliamida, resistente à alta temperatura, não resinado,com abertura de malha de 40 a $50 \mathrm{~mm}$. Foram colocados $6 \mathrm{~g}$ de amostra dos concentrados e $3 \mathrm{~g}$ de amostra do volumoso em cada saco, com três repetições para cada alimento, em todos os períodos de incubação e para todos os animais, totalizando 63 sacos por animal em cada dieta, sendo 54 incubados e nove utilizados para determinação da fração solúvel. Os períodos de incubação estudados foram 3, 6, 12, 24, 48 e 72 horas. Após a retirada do rúmen, os sacos foram lavados imediatamente em água corrente até que esta se tornasse clara. Os sacos destinados à determinação da fração solúvel foram lavados da mesma forma em água corrente. Todos os sacos, após essa lavagem, foram pré-secos a $60^{\circ} \mathrm{C}$ por 48 horas, moídos os resíduos a um milímetro e analisados para matéria seca, fibra em detergente neutro e nitrogênio, segundo metodologias descritas por Silva (1998), e amido, segundo Hendrix (1993).

Os efeitos das dietas sobre as variáveis de degradabilidade foram analisados através do delineamento em blocos em esquema de parcelas subdivididas e as degradabilidades potencial e efetiva através do delineamento em blocos, em que cada animal constituiu um bloco.

\section{Resultados e Discussão}

Na Tabela 3 encontram-se os resultados de taxa de passagem das dietas experimentais. Foram observadas diferenças $(\mathrm{P}<0,05)$ entre tratamentos, sendo que a dieta com farelo de soja apresentou taxa de passagem mais alta, o que reflete em uma reciclagem alimentar mais rápida com conseqüente esvaziamento
Tabela 3 - Resultados de taxa de passagem das dietas experimentais $(\% / h)^{1}$

Table 3 - Results of the passage rate of the experimental diets $(\% / h)^{1}$

\begin{tabular}{lcc}
\hline & \multicolumn{2}{c}{$\begin{array}{c}\text { Tratamento } \\
\text { Treatment }\end{array}$} \\
\cline { 2 - 3 } & $\begin{array}{c}\text { Farelo de soja } \\
\text { Soybean meal }\end{array}$ & $\begin{array}{c}\text { Glutenose } \\
\text { Corn gluten meal }\end{array}$ \\
\hline $\begin{array}{l}\text { Médias } \\
\text { Means } \\
\begin{array}{l}\text { Coeficiente de variação } \% \\
\text { Coefficient of variation }\end{array}\end{array}$ & $6,6 \mathrm{a}$ & $2,4 \mathrm{~b}$ \\
\hline
\end{tabular}

${ }^{1}$ Médias na mesma linha seguidas de letras diferentes diferem entre si pelo teste de Tukey $(P<0,05)$.

${ }^{1}$ Means followed by differents letters, within a row, are different by Tukey test $(P<.05)$.

do sistema digestivo, implicando maior consumo em animais de produção elevada. No presente trabalho, as ingestões de matéria seca foram de $10,2 \mathrm{~kg}$ por animal por dia, independente do tratamento, porque os animais eram adultos com elevado peso vivo.

Os valores das frações solúvel, insolúvel com potencial de degradação e indegradável e as taxas de degradação da fração potencialmente degradável da matéria seca das fontes nitrogenadas, do milho e do feno encontram-se nas Tabelas 4 e 5.

A glutenose apresentou solubilidade da matéria seca cerca de $50 \%$ menor $(\mathrm{P}<0,05)$ que o farelo de soja, o que lhe conferiu a característica de baixa solubilidade (Tabela 4). Os valores obtidos para a fração solúvel da matéria seca do farelo de soja são semelhantes aos obtidos por outros autores (Silva, 1999; Calixto, 2001). A fração B foi superior e a fração $\mathrm{C}$ inferior para o farelo de soja em relação à glutenose. A taxa de degradação $(2,0 \% / \mathrm{h})$ da fração $\mathrm{B}$ da glutenose foi mais baixa do que para o farelo de soja $(8,2 \% / h)$.

Entretanto o milho e o feno não apresentaram diferenças nestas variáveis (Tabela 5). Estes resultados já eram esperados para o milho, mas acreditavase haver influência da menor quantidade de PDR das dietas com glutenose no ambiente ruminal, refletindo em diferentes desaparecimentos da matéria seca do feno (Russell et al., 1992).

Quando foram analisados os resultados de degradabilidades potencial e efetiva (Tabela 6), confirmou-se a baixa disponibilidade ruminal da matéria seca da glutenose, cerca de $40 \%$ inferior ao farelo de soja. Rossi Jr. (1994) obteve valores de degradabilidade efetiva da matéria seca do farelo de soja de $77 \%$, valor superior ao obtido nesta pesquisa

\section{R. Bras. Zootec., v.31, n.5, p.2139-2148, 2002}


Tabela 4 - Frações solúvel (A), insolúvel com potencial de degradação (B), não degradável (C), taxas de degradação (c) da matéria seca do farelo de soja e da glutenose das dietas experimentais ${ }^{1}$

Table 4 - Soluble $(A)$, insoluble with potential of degradation $(B)$ and undegradable $(C)$ fractions, degradations rate (c) of dry matter of soybean meal and corn gluten meal of the experimental diets ${ }^{1}$

\begin{tabular}{lccc}
\hline $\begin{array}{l}\text { Variável } \\
\text { Variable }\end{array}$ & \multicolumn{3}{c}{$\begin{array}{c}\text { Dieta } \\
\text { Diet }\end{array}$} \\
\cline { 2 - 4 } & $\begin{array}{c}\text { Farelo de soja } \\
\text { Soybean meal }\end{array}$ & $\begin{array}{c}\text { Glutenose } \\
\text { Corn gluten meal }\end{array}$ & $\begin{array}{c}\text { Coeficiente de variação \% } \\
\text { Coefficient of variation }\end{array}$ \\
& \multicolumn{3}{c}{$\begin{array}{c}\text { Ingrediente } \\
\text { Ingredient }\end{array}$} \\
\cline { 2 - 4 } & Farelo de soja & Glutenose & 1,2 \\
A \% & Soybean meal & $15,6^{\mathrm{b}}$ & 6,5 \\
$\mathrm{~B} \%$ & $32,7^{\mathrm{a}}$ & $55,4^{\mathrm{b}}$ & 31,2 \\
$\mathrm{C} \%$ & $64,7^{\mathrm{a}}$ & $29,0^{\mathrm{a}}$ & 31,4 \\
$\mathrm{c} \% / \mathrm{h}$ & $2,6^{\mathrm{b}}$ & $2,0^{\mathrm{b}}$ & \\
\hline
\end{tabular}

${ }_{1}^{1}$ Médias seguidas de letras distintas, nas linhas, diferem pelo teste Tukey $(P<0,05)$.

${ }^{1}$ Means followed by different letters, within a row, are different $(P<.05)$ by Tukey test.

$(62,8 \%)$. Entretanto, as degradabilidades efetivas da matéria seca do milho e do feno foram favorecidas pela utilização de glutenose nas dietas.

Os valores das frações $\mathrm{A}, \mathrm{B}$ e $\mathrm{C}$ e as taxas de degradação $(c \% / h)$ do nitrogênio das fontes nitrogenadas, do milho e do feno das dietas encontram-se nas Tabelas 7 e 8 . A solubilidade do nitrogênio da glutenose foi inferior $(\mathrm{P}<0,05)$ à obtida para $\mathrm{o}$ farelo de soja, porém apresentou alta concentração de nitrogênio insolúvel e indegradável, resultando valores da fração B inferiores em relação aos obtidos para o farelo de soja.

À semelhança dos resultados obtidos para matéria seca, a taxa de degradação $(c \% / h)$ do nitrogênio da glutenose foi bem inferior $(1 \% / \mathrm{h})$ à do farelo de soja $(5,6 \% / h)$. Dutra et al. (1997) encontraram resultados semelhantes para a glutenose.

Segundo Cozzi et al. (1993), a baixa taxa de degradação do nitrogênio da glutenose é atribuída à sua natureza viscosa que forma uma massa gelatinosa nos sacos de náilon quando umedecidos no rúmen. Essa massa provavelmente diminui a superfície total da glutenose, reduzindo sua disponibilidade para a bactéria ruminal e podendo resultar no impedimento de pequenas partículas se moverem dentro do saco. Então, a natureza física da glutenose pode requerer metodologia específica que permita melhor resultado da degradabilidade ruminal.

Tabela 5 - Frações solúvel (A), insolúvel com potencial de degradação (B), não degradável (C), taxas de degradação (C) da matéria seca do milho e do feno das dietas experimentais ${ }^{1}$

Table 5 - Soluble $(A)$, insoluble with potential of degradation (B), non-degradable (C) fractions, degradations rate (c) of dry matter of corn and hay of the experimental diets ${ }^{1}$

\begin{tabular}{|c|c|c|c|c|c|}
\hline \multirow[t]{2}{*}{$\begin{array}{l}\text { Variável } \\
\text { Variable }\end{array}$} & \multicolumn{4}{|c|}{$\begin{array}{c}\text { Dieta } \\
\text { Diet }\end{array}$} & \multirow[t]{2}{*}{$\begin{array}{l}\text { Coeficiente de variação \% } \\
\text { Coefficient of variation }\end{array}$} \\
\hline & $\begin{array}{l}\text { Farelo de soja } \\
\text { Soybean meal }\end{array}$ & $\begin{array}{c}\text { Glutenose } \\
\text { Corn gluten meal }\end{array}$ & $\begin{array}{l}\text { Farelo de soja } \\
\text { Soybean meal }\end{array}$ & $\begin{array}{c}\text { Glutenose } \\
\text { Corn gluten meal }\end{array}$ & \\
\hline & \multicolumn{4}{|c|}{$\begin{array}{c}\text { Ingrediente } \\
\text { Ingredient }\end{array}$} & \\
\hline & \multicolumn{2}{|c|}{$\begin{array}{c}\text { Milho } \\
\text { Corn }\end{array}$} & \multicolumn{2}{|c|}{$\begin{array}{c}\text { Feno } \\
\text { Hay }\end{array}$} & \\
\hline A & $20,7^{\mathrm{a}}$ & $20,7^{\mathrm{a}}$ & $18,0^{\mathrm{a}}$ & $18,0^{\mathrm{a}}$ & 1,2 \\
\hline B & $73,4^{\mathrm{a}}$ & $75,4^{\mathrm{a}}$ & $36,5^{\mathrm{a}}$ & $43,3^{\mathrm{a}}$ & 6,5 \\
\hline C & $5,9 a$ & $3,9^{\mathrm{a}}$ & $45,5^{\mathrm{a}}$ & $43,5^{\mathrm{a}}$ & 31,2 \\
\hline $\mathrm{c} \% / \mathrm{h}$ & $4,6^{\mathrm{a}}$ & $5,7^{\mathrm{a}}$ & $2,9^{\mathrm{a}}$ & $3,6^{\mathrm{a}}$ & 31,4 \\
\hline
\end{tabular}

${ }^{1}$ Médias seguidas de letras distintas, nas linhas, diferem pelo teste Tukey $(\mathrm{P}<0,05)$, dentro de cada ingrediente.

${ }^{1}$ Means followed by different letters, within a row, are different $(P<.05)$ by Tukey test, inside each ingredient. 
Tabela 6 - Degradabilidades potencial e efetiva da matéria seca do farelo de soja, da glutenose, do milho e do feno das dietas experimentais

Table 6 - Potential and effective degradabilities of dry matter of soybean meal, corn gluten meal, corn and hay of experimental diets

\begin{tabular}{|c|c|c|c|c|}
\hline \multirow[t]{2}{*}{$\begin{array}{l}\text { Ingrediente } \\
\text { Ingredient }\end{array}$} & \multicolumn{4}{|c|}{$\begin{array}{l}\text { Dieta } \\
\text { Diet }\end{array}$} \\
\hline & $\begin{array}{l}\text { Farelo de soja } \\
\text { Soybean meal }\end{array}$ & $\begin{array}{c}\text { Glutenose } \\
\text { Corn gluten meal }\end{array}$ & $\begin{array}{c}\text { Farelo de soja } \\
\text { Soybean meal }\end{array}$ & $\begin{array}{c}\text { Glutenose } \\
\text { Corn gluten meal }\end{array}$ \\
\hline & \multicolumn{2}{|c|}{$\begin{array}{l}\text { Degradabilidade potencial }(\%) \\
\text { Potential degradability }\end{array}$} & \multicolumn{2}{|c|}{$\begin{array}{c}\text { Degradabilidade efetiva (\%) } \\
\text { Effective degradability }\end{array}$} \\
\hline $\begin{array}{l}\text { Farelo de soja }{ }^{1} \\
\text { Soybean meal }\end{array}$ & 90,9 & - & 62,8 & - \\
\hline $\begin{array}{l}\text { Glutenose }^{1} \\
\text { Corn gluten meal }\end{array}$ & - & 46,3 & - & 38,6 \\
\hline $\begin{array}{l}\text { Milho }^{2} \\
\text { Corn }^{2} \\
\text { Feno }^{2}\end{array}$ & $85,6^{\mathrm{a}}$ & $91,0^{\mathrm{a}}$ & $51,5^{\mathrm{b}}$ & $73,7^{\mathrm{a}}$ \\
\hline $\begin{array}{l}\text { Hay }^{2} \\
\text { Coeficiente de variação \% }\end{array}$ & $45,1^{\mathrm{a}}$ & $46,6^{\mathrm{a}}$ & $29,3^{b}$ & $40,6^{\mathrm{a}}$ \\
\hline Coefficient of variation & 5,8 & & 10,2 & \\
\hline
\end{tabular}

${ }^{1}$ Farelo de soja e glutenose diferem pelo teste Tukey $(\mathrm{P}<0,05)$, para uma mesma degradabilidade.

2 Médias seguidas de letras distintas, nas linhas, para uma mesma degradabilidade, diferem pelo teste de Tukey ( $<<0,05)$.

1 Soybean meal and corn gluten meal are different $(P<.05)$ by Tukey test, within each degradability.

2 Means followed by different letters, within a row, are different $(P<.05)$ by Tukey test, within each degradability.

Ha et al. (1986) observaram grande variação nos valores de degradação de diferentes amostras de grãos processados, provavelmente devido a diferenças no processamento ou exposição do material ao calor. Como a glutenose é um co-produto do milho, derivado da extração do amido para o consumo humano, poderia decorrer menor solubilidade (fração A) e menor ação fermentativa ruminal, representada pela menor fração B e menor taxa de degradação $(\mathrm{c} \% / \mathrm{h})$ obtidas para a glutenose comparativamente ao milho.
Cozzi \& Polan (1994) obtiveram resultados de taxa de degradação extremamente baixa, $0,44 \% / \mathrm{h}$, para o nitrogênio da glutenose fornecida para vacas em lactação. O seu valor de A foi de apenas 3,8\%, inferior aos obtidos neste experimento, o valor de B foi $49,4 \%$, semelhante, e o de $\mathrm{C}, 46,6 \%$, mais elevado. As degradabilidades efetivas a 5 e $8 \% / \mathrm{h}$ foram muito baixas, de 8,1 e 6,6\%. Quando utilizaram a modificação da metodologia in situ de Cozzi et al. (1993), que indicou a adição de fontes de fibra nos sacos de náilon com a finalidade de eliminar a possibilidade de formar

Tabela 7 - Frações solúvel (A), insolúvel com potencial de degradação (B), não degradável (C), taxas de degradação (c) do nitrogênio do farelo de soja e da glutenose das dietas experimentais ${ }^{1}$

Table 7 - Soluble $(A)$, insoluble with degradation potential $(B)$ and undegradable (C) fractions, degradations rate (c) of nitrogen of soybean meal and corn gluten meal of the experimental diets ${ }^{1}$

\begin{tabular}{|c|c|c|c|}
\hline \multirow[t]{2}{*}{$\begin{array}{l}\text { Variável } \\
\text { Variable }\end{array}$} & \multicolumn{2}{|c|}{$\begin{array}{l}\text { Dieta } \\
\text { Diet }\end{array}$} & \multirow[t]{2}{*}{$\begin{array}{c}\text { Coeficiente de variação \% } \\
\text { Coefficient of variation }\end{array}$} \\
\hline & $\begin{array}{l}\text { Farelo de soja } \\
\text { Soybean meal }\end{array}$ & $\begin{array}{c}\text { Glutenose } \\
\text { Corn gluten meal }\end{array}$ & \\
\hline & \multicolumn{2}{|c|}{$\begin{array}{l}\text { Ingrediente } \\
\text { Ingredient }\end{array}$} & \\
\hline & $\begin{array}{c}\text { Farelo de soja } \\
\text { Soybean meal }\end{array}$ & $\begin{array}{c}\text { Glutenose } \\
\text { Corn gluten meal }\end{array}$ & \\
\hline A\% & $35,4^{\mathrm{a}}$ & $20,4^{b}$ & 16,0 \\
\hline $\mathrm{B} \%$ & $61,9^{\mathrm{a}}$ & $50,6^{\mathrm{b}}$ & 5,1 \\
\hline $\mathrm{C} \%$ & $2,7^{\mathrm{b}}$ & $29,0^{\mathrm{a}}$ & 30,1 \\
\hline $\mathrm{c} \% / \mathrm{h}$ & $5,6^{\mathrm{a}}$ & $1,0^{\mathrm{b}}$ & 34,6 \\
\hline
\end{tabular}

${ }_{1}^{1}$ Médias seguidas de letras distintas, nas linhas, diferem entre si pelo teste de Tukey $(P<0,05)$.

${ }^{1}$ Means followed by different letters within a row, are different by Tukey test $(P<.05)$. 
essa massa gelatinosa descrita anteriormente, os valores de taxa de degradação se elevaram para $2,5 \% /$ h e a fração B se elevou para $85 \%$, considerando 120 horas para o potencial de degradação. Cozzi et al. (1993) obtiveram degradabilidade efetiva do $\mathrm{N}$ da glutenose com $\mathrm{kp}$ de $6 \%$ /h de $20,7 \%$, e, quando utilizaram fibra para a incubação da glutenose, esse valor se elevou para $28 \%$, em média. Esse valor corrigido de degradabilidade efetiva do nitrogênio é inferior ao obtido neste trabalho. Esses fatores, juntamente com diferenças observadas em função da dieta e nível de consumo, tornam difícil a comparação dos resultados de degradação de alimentos concentrados.

Os resultados da cinética de degradabilidade do nitrogênio da Tabela 8 mostram que o milho manteve, tanto para a dieta com farelo de soja quanto para a dieta com glutenose, valores praticamente inalterados das frações $\mathrm{A}, \mathrm{B}$ e $\mathrm{C}$, com pequeno aumento na taxa de degradação (c\%/h), quando se utilizou glutenose. Na literatura existente sobre cinética ruminal, observa-se que o milho se comporta de forma praticamente imutável, mesmo quando as dietas são diferentes quanto à fibra efetiva, qualidade nutricional da fibra ou da proteína da dieta (Silva, 1999; Calixto, 2001; Galati et al., 2002). Entretanto o feno apresentou redução significativa na taxa de degradação do nitrogênio, quando se utilizou glutenose como fonte protéica na dieta, sugerindo que o tempo de permanência do feno no rúmen seria fator determinante da extensão da sua degradação.
$\mathrm{Na}$ Tabela 9, encontram-se os resultados de degradabilidades potencial e efetiva do nitrogênio dos ingredientes utilizados nas dietas. As degradabilidades potencial e efetiva do nitrogênio da glutenose foram inferiores às obtidas para o farelo de soja, confirmando a literatura (NRC, 1986, 1989, 2001). Convém ressaltar que os valores de degradabilidades efetivas obtidos foram derivados da utilização da taxa de passagem $2,4 \% / \mathrm{h}$ para a dieta com glutenose e $6,6 \%$ / $\mathrm{h}$ para a dieta com farelo de soja.

A degradabilidade efetiva do nitrogênio do milho na dieta com farelo de soja foi inferior à obtida na dieta com glutenose. Isto também ocorreu com as degradabilidades potencial e efetiva do nitrogênio do feno. Uma possível explicação para esse resultado seria a elevada taxa de passagem obtida com o fornecimento das dietas com farelo de soja. As degradabilidades potencial e efetiva do nitrogênio do farelo de soja foram praticamente o dobro das obtidas para a glutenose, possivelmente garantindo o aporte nitrogenado necessário ao rúmen.

Na Tabela 10, encontram-se os resultados obtidos para as frações A, B e C e as taxas de degradação do amido das fontes nitrogenadas e do milho das dietas. Observaram-se diferenças $(\mathrm{P}<0,05)$ na solubilidade do amido para as diferentes fontes nitrogenadas.

A pequena quantidade de amido presente no farelo de soja $(8,9 \%)$ apresentou alta solubilidade. $\mathrm{O}$ potencial máximo de degradação do farelo de soja e da glutenose foi atingido rapidamente. Com 48 horas

Tabela 8 - Frações solúvel $(A)$, insolúvel com potencial de degradação (B), não degradável (C), taxas de degradação (c) do nitrogênio do milho e do feno das dietas experimentais

Table 8 - Soluble $(A)$, insoluble with degradation potential $(B)$ and undegradable $(C)$ fractions, degradations rate $(C)$ of nitrogen of corn and hay of the experimental diets

\begin{tabular}{|c|c|c|c|c|c|}
\hline \multirow[t]{2}{*}{$\begin{array}{l}\text { Variável } \\
\text { Variable }\end{array}$} & \multicolumn{4}{|c|}{$\begin{array}{c}\text { Dieta } \\
\text { Diet }\end{array}$} & \multirow[t]{2}{*}{$\begin{array}{c}\text { Coeficiente de variação \% } \\
\text { Coefficient of variation }\end{array}$} \\
\hline & $\begin{array}{l}\text { Farelo de soja } \\
\text { Soybean meal }\end{array}$ & $\begin{array}{c}\text { Glutenose } \\
\text { Corn gluten meal }\end{array}$ & $\begin{array}{l}\text { Farelo de soja } \\
\text { Soybean meal }\end{array}$ & $\begin{array}{c}\text { Glutenose } \\
\text { Corn gluten meal }\end{array}$ & \\
\hline
\end{tabular}

\begin{tabular}{|c|c|c|c|c|c|}
\hline \multirow[b]{3}{*}{ A } & \multicolumn{4}{|c|}{$\begin{array}{l}\text { Ingrediente } \\
\text { Ingredient }\end{array}$} & \\
\hline & \multicolumn{2}{|c|}{$\begin{array}{l}\text { Milho } \\
\text { Corn }\end{array}$} & \multicolumn{2}{|c|}{$\begin{array}{c}\text { Feno } \\
\text { Hay }\end{array}$} & \\
\hline & $11,3^{\mathrm{a}}$ & $11,3^{b}$ & $34,3^{\mathrm{a}}$ & $34,3^{\mathrm{a}}$ & 16,0 \\
\hline B & $87,5^{\mathrm{a}}$ & $87,1^{\mathrm{a}}$ & $30,7^{\mathrm{a}}$ & $30,8^{a}$ & 5,1 \\
\hline $\mathrm{C}$ & $1,2^{\mathrm{a}}$ & $1,6^{\mathrm{a}}$ & $5,0^{\mathrm{a}}$ & $4,9^{\mathrm{a}}$ & 30,1 \\
\hline $\mathrm{c} \% / \mathrm{h}$ & $4,0^{\mathrm{a}}$ & $5,1^{\mathrm{a}}$ & $8,9^{\mathrm{a}}$ & $2,1^{\mathrm{b}}$ & 34,6 \\
\hline
\end{tabular}

${ }^{1}$ Médias seguidas de letras distintas, nas linhas, diferem pelo teste Tukey $(\mathrm{P}<0,05)$, dentro de cada ingrediente.

${ }^{1}$ Means followed by different letters, within a row, are different $(P<.05)$ by Tukey test, within each ingredient.

R. Bras. Zootec., v.31, n.5, p.2139-2148, 2002 
Tabela 9 - Degradabilidades potencial e efetiva do nitrogênio do farelo de soja, da glutenose, do milho e do feno das dietas experimentais

Table 9 - Potential and effective degradabilities of nitrogen of soybean meal, corn gluten meal, corn and hay of the experimental diets

\begin{tabular}{|c|c|c|c|c|}
\hline \multirow[t]{2}{*}{$\begin{array}{l}\text { Ingrediente } \\
\text { Ingredient }\end{array}$} & \multicolumn{4}{|c|}{$\begin{array}{c}\text { Dieta } \\
\text { Diet }\end{array}$} \\
\hline & $\begin{array}{l}\text { Farelo de soja } \\
\text { Soybean meal }\end{array}$ & $\begin{array}{c}\text { Glutenose } \\
\text { Corn gluten meal }\end{array}$ & $\begin{array}{l}\text { Farelo de soja } \\
\text { Soybean meal }\end{array}$ & $\begin{array}{c}\text { Glutenose } \\
\text { Corn gluten meal }\end{array}$ \\
\hline & \multicolumn{2}{|c|}{$\begin{array}{c}\text { Degradabilidade potencial }(\%) \\
\text { Potential degradability }\end{array}$} & \multicolumn{2}{|c|}{$\begin{array}{c}\text { Degradabilidade efetiva }(\%) \\
\text { Effective degradability }\end{array}$} \\
\hline $\begin{array}{l}\text { Farelo de soja }{ }^{1} \\
\text { Soybean meal }\end{array}$ & 90,3 & - & 62,9 & - \\
\hline Glutenose $^{1}$ & - & 39,7 & - & 35,7 \\
\hline $\begin{array}{l}\text { Corn gluten meal } \\
\text { Milho }^{2} \\
\text { Corn }^{2}\end{array}$ & $88,4^{\mathrm{a}}$ & $87,8^{\mathrm{a}}$ & $56,3^{\mathrm{b}}$ & $68,7 \mathrm{a}$ \\
\hline $\begin{array}{l}\text { Feno }^{2} \\
\text { Hay }^{2}\end{array}$ & $93,0^{\mathrm{a}}$ & $76,6^{\mathrm{b}}$ & $55,4^{\mathrm{b}}$ & $68,9^{\mathrm{a}}$ \\
\hline $\begin{array}{l}\text { Coeficiente de variação \% } \\
\text { Coefficient of variation }\end{array}$ & \multicolumn{2}{|c|}{6,0} & \multicolumn{2}{|c|}{11,8} \\
\hline
\end{tabular}

${ }_{1}$ Farelo de soja e glutenose diferem $(\mathrm{P}<0,05)$ para uma mesma degradabilidade.

2 Médias seguidas de letras distintas, nas linhas para uma mesma degradabilidade, diferem $(P<0,05)$ pelo teste Tukey.

1 Soybean meal and corn gluten meal are different $(P<.05)$ inside each degradability.

${ }^{2}$ Means followed by different letters, within the row, are different $(P<.05)$ by Tukey test, within each degradability.

de degradação, a totalidade do amido havia sido degradada (observação experimental). O valor mais baixo de solubilidade do amido foi obtido para a glutenose. a glutenose, que também apresentou baixo valor da fração C (3,3\%). As taxas de degradação do nitrogênio do milho foram semelhantes para as duas dietas, mas o feno apresentou maior valor para a dieta com farelo de soja.

Com isso, a glutenose foi o ingrediente protéico que apresentou a mais alta fração $B$ e a mais alta taxa de degradação do amido. Esse comportamento do amido da glutenose pode ser atribuído à gelatinização decorrente do processamento e calor necessários à sua obtenção que lhe confere maior utilização no ambiente ruminal (Meirelles, 2001; Ferreira, 2001).

Quanto ao amido do milho, cinco dos seis animais apresentaram $97 \%$ de desaparecimento a 48 horas de incubação e um a 24 horas, para a dieta com glutenose (observações experimentais). A cinética de degradação ruminal do amido do milho não apresentou efeito da utilização de uma ou de outra fonte protéica (Tabela 10). Portanto, a utilização ruminal do amido do milho foi independente da degradabilidade ou mesmo da solubilidade ruminal da fonte de nitrogênio da dieta, quando não se considerou a velocidade de passagem das dietas.
$\mathrm{Na}$ Tabela 11, encontram-se as degradabilidades potencial e efetiva do amido das fontes nitrogenadas e do milho. As degradabilidades potenciais do amido das fontes nitrogenadas não diferiram e apresentaram valores elevados, mas a degradabilidade efetiva do amido da glutenose foi superior à do farelo de soja. A matéria seca da glutenose apresentou teor de amido de 38,0\% e, conseqüentemente, $34 \%$ de amido efetivamente degradado, considerando o valor $88,4 \%$ obtido para a sua degradabilidade efetiva.

A degradabilidade efetiva do amido do milho foi maior para as dietas com glutenose (Tabela 11), possivelmente em decorrência da demanda energética ruminal para a degradação da fibra da dieta, que se pode observar na Tabela 12. Embora não apresente significativa diferença, provavelmente em decorrência do coeficiente de variação obtido $(18,2 \%)$, a taxa de degradação da FDN do feno foi $65 \%$ superior na dieta com glutenose em relação à dieta com farelo de soja. A degradabilidade potencial da FDN do feno não apresentou efeito da fonte protéica, mas a degradabilidade efetiva foi superior quando se utilizou glutenose nas dietas experimentais à degradabilidade efetiva quando quando se utilizou o farelo de soja. 
Tabela 10 - Frações solúvel (A), insolúvel com potencial de degradação (B), não degradável (C), taxas de degradação (c) do amido do farelo de soja, da glutenose e do milho das dietas experimentais

Table 10 - Soluble (A), insoluble with potential of degradation (B), non-degradable (C) fractions, degradations rate (c) of starch of soybean meal, corn gluten meal and corn of the experimental diets

\begin{tabular}{|c|c|c|c|c|c|}
\hline \multirow[t]{2}{*}{$\begin{array}{l}\text { Variável } \\
\text { Variable }\end{array}$} & \multicolumn{4}{|c|}{$\begin{array}{l}\text { Dieta } \\
\text { Diet }\end{array}$} & \multirow[t]{2}{*}{$\begin{array}{l}\text { Coeficiente de variação \% } \\
\text { Coefficient of variation }\end{array}$} \\
\hline & $\begin{array}{l}\text { Farelo de soja } \\
\text { Soybean meal }\end{array}$ & $\begin{array}{c}\text { Glutenose } \\
\text { Corn gluten meal }\end{array}$ & $\begin{array}{c}\text { Farelo de soja } \\
\text { Soybean meal }\end{array}$ & $\begin{array}{c}\text { Glutenose } \\
\text { Corn gluten meal }\end{array}$ & \\
\hline & \multicolumn{4}{|c|}{$\begin{array}{c}\text { Ingrediente } \\
\text { Ingredient } \\
\end{array}$} & \\
\hline & \multicolumn{2}{|c|}{$\begin{array}{l}\text { Milho } \\
\text { Corn }\end{array}$} & \multicolumn{2}{|c|}{$\begin{array}{c}\text { Feno } \\
\text { Hay }\end{array}$} & \\
\hline A\% & $43,0^{\mathrm{a}}$ & $32,0^{b}$ & 36,3 & 36,3 & 4,4 \\
\hline $\mathrm{B} \%$ & $55,7^{\mathrm{a}}$ & $64,7^{b}$ & 46,4 & 46,7 & 6,7 \\
\hline $\mathrm{C} \%$ & $1,3^{\mathrm{a}}$ & $3,3^{\mathrm{a}}$ & 17,3 & 17,0 & 29,0 \\
\hline $\mathrm{c} \% / \mathrm{h}$ & $7,6^{\mathrm{b}}$ & $16,1^{\mathrm{a}}$ & 3,4 & 3,8 & 22,0 \\
\hline
\end{tabular}

${ }_{1}^{1}$ Médias seguidas de letras distintas, nas linhas, diferem $(P<0,05)$ pelo teste Tukey.

${ }^{2}$ As médias obtidas para o milho não diferiram $(P>0,05)$ entre dietas.

${ }^{1}$ Means followed by different letters, within a row, are different by Tukey test.

2 Means of corn are not different, between diets $(P>.05)$.

Tabela 11 - Degradabilidades potencial e efetiva do amido do farelo de soja e glutenose e do milho nas dietas experimentais

Table 11 - Potential and effective degradabilities of starch of soybean meal, corn gluten meal and corn of the experimental diets.

\begin{tabular}{|c|c|c|c|c|}
\hline \multirow[t]{2}{*}{$\begin{array}{l}\text { Ingrediente } \\
\text { Ingrediets }\end{array}$} & \multicolumn{4}{|c|}{$\begin{array}{c}\text { Dieta } \\
\text { Diet }\end{array}$} \\
\hline & $\begin{array}{l}\text { Farelo de soja } \\
\text { Soybean meal }\end{array}$ & $\begin{array}{c}\text { Glutenose } \\
\text { Corn gluten meal }\end{array}$ & $\begin{array}{l}\text { Farelo de soja } \\
\text { Soybean meal }\end{array}$ & $\begin{array}{c}\text { Glutenose } \\
\text { Corn gluten meal }\end{array}$ \\
\hline & \multicolumn{2}{|c|}{$\begin{array}{c}\text { Degradabilidade potencial (\%) } \\
\text { Potential degradability }\end{array}$} & \multicolumn{2}{|c|}{$\begin{array}{c}\text { Degradabilidade efetiva (\%) } \\
\text { Effective degradability }\end{array}$} \\
\hline $\begin{array}{l}\text { Farelo de soja }{ }^{1} \\
\text { Soybean meal }\end{array}$ & 96,6 & - & 72,4 & - \\
\hline $\begin{array}{l}\text { Glutenose }^{1} \\
\text { Corn gluten meal }\end{array}$ & - & 96,6 & - & 88,4 \\
\hline $\begin{array}{l}\text { Milho }^{2} \\
\text { Corn }^{2}\end{array}$ & $73,5^{\mathrm{a}}$ & $74,8^{\mathrm{a}}$ & $52,5^{\mathrm{b}}$ & $68,0^{\mathrm{a}}$ \\
\hline $\begin{array}{l}\text { Coeficiente de variação \% } \\
\text { Coefficient of variation }\end{array}$ & \multicolumn{2}{|c|}{4,5} & \multicolumn{2}{|c|}{5,1} \\
\hline
\end{tabular}

A maior degradabilidade efetiva da fibra do feno observada na dieta com glutenose pode estar relacionada ao fato de não promover alteração na atividade microbiana, no $\mathrm{pH}$ ruminal ou aumento na taxa de diluição do rúmen, com conseqüente diminuição do tempo de exposição da fibra ao ataque de bactérias celulolíticas, por ser a glutenose uma fonte protéica de baixa degradabilidade ruminal (Petit, 1994). A glutenose possui elevado valor de fração B $(54,7 \%)$ para o amido, com igualmente elevada taxa de degradação $(16,1 \% / \mathrm{h})$, além de grande aporte de amido (38,0\%/MS), o que pode ter proporcionado adequado fornecimento de energia ao ambiente ruminal, contribuindo, consequientemente, para elevar a degradação da FDN. Este resultado vem reforçar observações de Zerbini \& Polan et al. (1985), Garnsworth (1989) e Holter et al. (1992) de que a adição de fonte protéica de baixa degradabilidade pode resultar em melhor 
Tabela 12 - Frações solúvel (A), insolúvel com potencial de degradação (B), não degradável (C), taxas de degradação (c) e degradabilidades potencial (DP) e efetiva (DE) da FDN do feno das dietas experimentais ${ }^{1}$

Table 12 - Soluble $(A)$, insoluble with potential of degradation $(B)$ and undegradable $(C)$ fractions, degradations rate $(c \% / h)$ and potencial $(P D)$ and effective $(E D)$ degradabilities of NDF of hay of the experimental diets

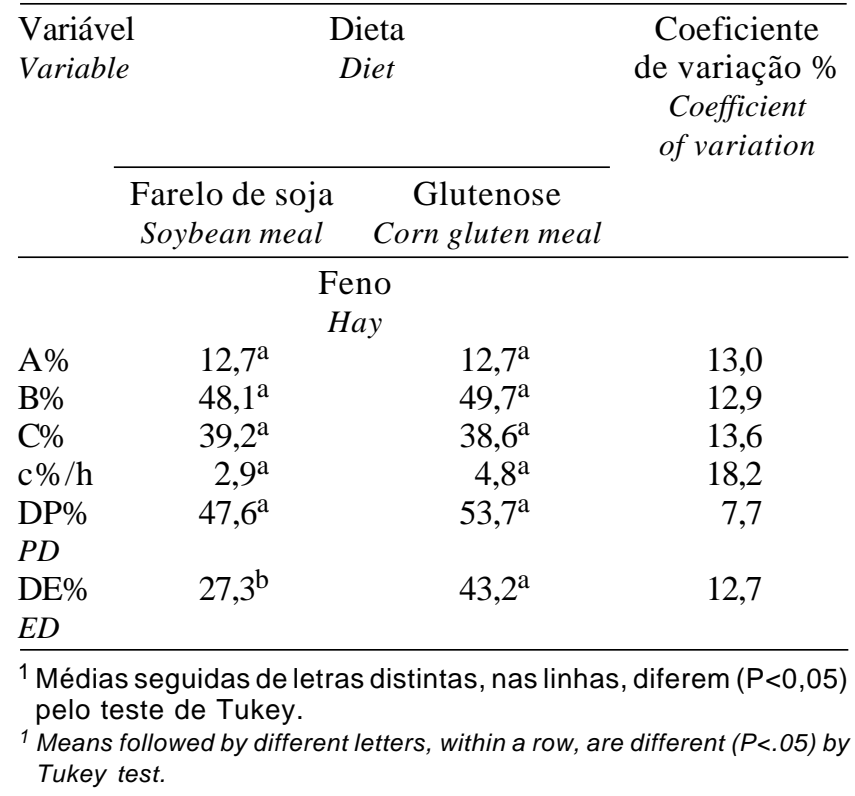

aproveitamento da fibra. Martins (2001) obteve maior digestibilidade da FDN no trato digestivo total quando utilizou a glutenose nas dietas do que quando utilizou o farelo de soja ou a uréia, resultados semelhantes aos deste trabalho. Entretanto, Ezequiel et al. (2001b), também utilizando a silagem de milho como volumoso, obtiveram maior digestibilidade in vitro da FDA de dietas que utilizavam uréia do que daquelas que utilizavam farelo de algodão, que possui nitrogênio menos degradável do que a uréia. Entretanto Ezequiel et al. (2001a), trabalhando com ovinos e utilizando o mesmo volumoso, encontraram digestibilidade in vivo da FDN menor para a dieta com uréia do que para a dieta com farelo de algodão. Tais resultados poderiam indicar que a digestibilidade ou a degradabilidade da fibra estariam envolvidas com outras características dietéticas além da degradabilidade ruminal do nitrogênio. Adamu et al. (1998) investigaram os efeitos de diferentes fontes de nitrogênio com diversas degradabilidade utilizando a silagem de milho e novilhos em crescimento. Concluíram que o fator que influenciou mais intensamente a eficiência da suplementação nitrogenada foi a concentração e não a qualidade do nitrogênio, porque a conversão alimentar diminuiu apenas quando o nitrogênio dietético atingiu 1,92\% (12\% de proteína bruta). Mucio (2001) confirmou essas afirmações ao obter semelhantes digestibilidades ruminal e intestinal da matéria seca, energia, nitrogênio, FDN e carboidratos totais de dietas contendo farelo de soja, glutenose ou uréia como fontes nitrogenadas e silagem de milho como volumoso.

\section{Conclusões}

A glutenose apresentou-se como uma fonte nitrogenada de baixa degradabilidade e baixa solubilidade, tanto da matéria seca quanto do nitrogênio, comparada ao farelo de soja. A maior degradabilidade efetiva da fibra do volumoso da dieta com glutenose foi atribuída à sua menor taxa de passagem.

\section{Literatura Citada}

ADAMU, A.M.; RUSSEL. J.R., TRENKLE, A. Effects of ruminal degradability of the protein supplement on the utilization of maize-stover silage by growing beef cattle. Animal Feed Science and Technology, v.20, n.3, p.241-250, 1998 .

CALIXTO, M.G. Efeito da monensina sobre a degradabilidade de ingredientes de rações contendo bagaço hidrolisado e subproduto da produção de lisina. Jaboticabal: Universidade Estadual Paulista, 2001. 75p. Monografia (Graduação em Zootecnia) - Universidade Estadual Paulista, 2001.

COZZI, G.; POLAN, G.E. Corn gluten meal or dried brewers grains as partial replacement for soybean meal in the diet of holstein cows. Journal of Dairy Science, v.77, n.3, p.825834, 1994.

COZZI, G.; BITTANTE, G.; POLAN, G.E. Comparison of fibrous materials as modifiers of in situ ruminal degradation of corn gluten meal. Journal of Dairy Science, v.76, n.4, p.1106-1113, 1993.

DUTRA, A.R.; QUEIROZ, A.C.; PEREIRA, J.C. Efeitos de níveis de fibra e das fontes de proteína sobre o consumo e digestão dos nutrientes em novilhos. Revista da Sociedade Brasileira de Zootecnia, v.25, n.4, p.787-796, 1997.

EZEQUIEL, J.M.B.; MATARAZZO, S.V.; SALMAN, A.K.D. et al. Digestibilidade aparente da energia e da fibra de dietas para ovinos contendo uréia, amiréia ou farelo de algodão. Revista Brasileira de Zootecnia, v.30, n.1, p.231-235, 2001a.

EZEQUIEL, J.M.B; SOARES, W.V.; SEIXAS, J.R.C. Digestibilidade in vitro da matéria seca, nitrogênio e fibra em detergente ácido de dietas completas contendo farelo de algodão, uréia ou amiréia. Revista Brasileira de Zootecnia, v.30, n.1, p.236-241, 2001 b.

FERREIRA, R.N. Degradação ruminal e digestibilidades intestinal e total da proteína do milho e dos germens de milho. Jaboticabal: Universidade Estadual Paulista, 2001. 113p. Tese (Doutorado em Zootecnia) - Universidade Estadual Paulista, 2001.

GALATI, R.L.; EZEQUIEL, J.M.B.; MENDES, A.R. et al. Cinética da digestão ruminal in situ de fontes energéticas

R. Bras. Zootec., v.31, n.5, p.2139-2148, 2002 
fornecidas a bovinos. In: REUNIÃO ANUAL DA SOCIEDADE BRASILEIRA DE ZOOTECNIA, 39., 2002, Recife. Anais... Recife: 2002 (CD ROM)

GARNSWORTHY, P.C. The interaction between dietary fiber level and protein degradability in dairy cows. Animal Production, v.48, n.1, p.271-281, 1989.

HA, J.K.; KENNELY, J.J.: BERZINS, R. Effect of dietary nitrogen source on microbial protein synthesis, dietary protein degradation and nutrient digestion of steers. Animal Feed Science and Technology, v.14, n.1, p.117-126, 1986.

HENDRIX, D.L. Rapid extration and analysis of nonstructural carbohydrates in plant tissues. Crop Science, v.33, n.6, p.1306-1311, 1993.

HOLTER, J.B.; HAYES, H.H.; URBAN Jr., W.E. et al. Response of holstein cows to corn gluten meal used to increase undegradable protein in early or later lactation. Jounal of Dairy Science, v.75, n.6, p.1495-1506, 1992.

MARTINS, C.G. Influência da suplementação protéica na digestibilidade da fibra e de outros nutrientes da silagem de milho. Jaboticabal: Universidade Estadual Paulista, 2001. 33p. Monografia (Graduação em Zootecnia) - Universidade Estadual Paulista, 2001.

McALLAN, A.B.; COCKBURN, J.E.; WILLIAMS, A.P. et al. The degradation of different protein supplements in the rumen of steers and the effects of these supplements on carbohydrate digestion. British Journal of Nutrition, v.60, n.3, p.669-682, 1998.

MEHREZ, A.Z.; ORSKOV, E.R. A study of the artificial fiber bag technique for determining the digestibility of feeds in the rumen. Journal of Agricultural Science, v.88, n.3, p.645650, 1977.

MEIRELLES, S.L. Degradabilidade ruminal in situ do milho e gérmen de milho extrusados ou não contendo dois níveis de óleo residual. Jaboticabal: Universidade Estadual Paulista, 2001. 44p. Monografia (Graduação em Zootecnia) Universidade Estadual Paulista, 2001.

MUCIO, C.R. Influência da degradabilidade da proteína na digestibilidade ruminal e pós-ruminal dos nutrientes da silagem de milho. Jaboticabal: Universidade Estadual Paulista, 2001. 24p. Monografia (Graduação em Zootecnia) - Universidade Estadual Paulista, 2001.

NATIONAL RESEARCH COUNCIL - NRC. Nutrient requirements of dairy cattle. 6.ed. Washington. D.C.: 1989. 157p.

NATIONAL RESEARCH COUNCIL - NRC. Nutrient requirements of beef cattle. 7.ed. Washington., D.C.: 1996. 242p.

NATIONAL RESEARCH COUNCIL - NRC. Nutrient requirements of dairy cattle. 7.ed. Washington. D.C.: 2001. 157p.

ORSKOV, E.R.; McDONALD, I. The estimation of protein degradability in the rumen from incubation measurements weighted according to rate of passage. Journal of Agriculture Science, v.92, n.2, p.499-503, 1979.
PEREIRA, J.R.A.; ROSSI Jr., P. Manual prático de avaliação nutricional de alimentos. Piracicaba: Fundação de Estudos Agrários "Luiz de Queiroz", 1994. 25p.

PETIT, H.V.; RIOUX, R.; TREMBLAY, G.F. Evaluation of forages and concentrates by the in situ degradability technique. In: SIMPÓSIO INTERNACIONAL DE PRODUÇÃO DE RUMINANTES. REUNIÃO ANUAL DA SOCIEDADE BRASIELIRA DE ZOOTECNIA, 31., 1994, Maringá. Anais... Maringá: Sociedade Brasileira de Zootecnia, 1994. p.1119-1133.

POLAN, C.E.; CUMMINS, K.; SNIFFEN, C.J. et al. Responses of dairy cows to supplemental rumen protected forms of methionine and lysine. Journal of Dairy Science, v.74, n.12, p.2997-3013, 1991.

ROSSI Jr., P. Degradabilidade ruminal dos componentes da fração nitrogenada e de carboidratos de silagem de milho, farelo de soja e sorgo grão, em bovinos da raça nelore. Piracicaba: Escola Superior de Agricultura "Luiz de Queiroz 1994. 90p. Dissertação (Mestrado em Ciência Animal) - Escola Superior de Agricultura "Luiz de Queiroz, 1994.

RUSSELL, J.B.; O'CONNOR, J.D.; FOX, D.G. et al. A net carbohydrate and protein system for evaluating cattle diets: 1. Ruminal fermentation. Journal of Animal Science, v.70, n.11, p.3551-3561, 1992.

SILVA, D.J. Análise de alimentos (Métodos químicos e biológicos). 2.ed. Viçosa, MG: Universidade Federal de Viçosa, 1998. $165 \mathrm{p}$.

SILVA, L.D.F. Degradabilidade ruminal da casca de soja e fontes protéicas e seus efeitos nas digestibilidades ruminal e intestinal de rações de bovinos. Jaboticabal: Universidade Estadual Paulista, 1999. 110p. Tese (Doutorado em Zootecnia) - Universidade Estadual Paulista, 1999.

STOKES, S.R.; HOOVER, W.H.; MILLER, T.K. et al. Ruminal digestion and microbial utilization of diets varying intake of carbohydrate and protein. Journal of Dairy Science, v.74, n.3, p.871-881, 1991.

ÚDEN, P.; COLLUCCI, P.E.; Van SOEST, P.J. Investigation of chromium, cerium and cobalt as marker in digesta. Rate of passage studies. Journal of the Science and Food Agriculture, v.31, n.7, p.625-632, 1980.

ZERBINI, E.; POLAN, C.E. Protein sources evaluated for ruminating holstein calves. Journal of Dairy Science, v.68, n.6, p.1416-1424, 1985. 